\title{
CONCEPTUALIZATIONS OF THE SOCIETAL PERSPECTIVE WITHIN ECONOMIC EVALUATIONS: A SYSTEMATIC REVIEW
}

Ruben M.W.A. Drost

Department of Health Services Research, Care and Public Health Research Institute (CAPHRI) Faculty of Health, Medicine and Life Sciences, Maastricht University

r.drost@maastrichtuniversity.nl

Ingeborg M. van der Putten

Department of Health Services Research, Care and Public Health Research Institute (CAPHRI), Faculty of Health, Medicine and Life Sciences, Maastricht University

Dirk Ruwaard

Department of Health Services Research, Care and Public Health Research Institute (CAPHRI)

Faculty of Health, Medicine and Life Sciences, Maastricht University

\author{
Silvia M.A.A. Evers \\ Department of Health Services Research, Care and Public Health Research Institute (CAPHRI) \\ Faculty of Health, Medicine and Life Sciences, Maastricht University \\ Trimbos, Netherlands Institute of Mental Health and Addiction \\ Aggie T.G. Paulus \\ Department of Health Services Research, Care and Public Health Research Institute (CAPHRI) \\ Faculty of Health, Medicine and Life Sciences, Maastricht University
}

Objectives: The aim of this study was to investigate how the societal perspective is conceptualized in economic evaluations and to assess how intersectoral costs and benefits (ICBs), that is, the costs and benefits pertaining to sectors outside the healthcare sector, impact their results.

Methods: Based on a search in July 2015 using PubMed, Embase, CINAHL, and PsychINF0, a systematic literature review was performed for economic evaluations which were conducted from a societal perspective. Conceptualizations were assessed in NVivo version 11 using conventional and directed content analysis. Trial-based evaluations in the fields of musculoskeletal and mental disorders were analyzed further, focusing on the way ICBs impact the results of economic evaluations.

Results: A total of 107 studies were assessed, of which 74 (69.1 percent) provided conceptualizations of the societal perspective. These varied in types of costs included and in descriptions of cost bearers. Labor productivity costs were included in seventy-two studies (67.3 percent), while only thirty-eight studies (35.5 percent) included other ICBs, most of which entailed informal care and/or social care costs. ICBs within the educational and criminal justice sectors were each included five times. Most of the trial-based evaluations analyzed further $(n=21$ of 28 ) reported productivity costs. In nine, these took up more than 50 percent of total costs. In several studies, criminal justice and informal care costs were also important.

Conclusions: There is great variety in the way the societal perspective is conceptualized and interpreted within economic evaluations. Use of the term "societal perspective" is often related to including merely productivity costs, while other ICBs could be relevant as well.

Keywords: Economic evaluation, Costs and cost analysis, Intersectoral costs and benefits, Societal perspective, Systematic literature review

Increasingly, health economic evaluations are being considered supportive for decision making on healthcare interventions $(1 ; 2)$. Because financial resources are scarce and investment options are infinite, it is important that these programs and interventions are effective not only in terms of health gains and improving quality of life, but that these effects also outweigh the costs of the intervention and the costs of service use in comparison with the best alternative investment in terms of costs for society as a whole. The analyses and reported results of such economic evaluations depend on the perspective from which the economic evaluation is conducted (3). This perspective can be either narrow, in which a selection of costs and effects are

This research was supported by grant 200400010 from the Dutch Organisation for Health Research and Development (ZonMw), The Hague. measured and included in the analysis, or broad, comprising all costs and effects of the interventions under comparison.

Within health economic evaluations, the most commonly used perspectives include (i) the payer perspective, in which only the costs and effects for a certain party, such as the patient, employer, or insurer, are included; (ii) the healthcare perspective, which comprises only the costs and effects within the healthcare sector; and (iii) the societal perspective, in which the analyst considers all costs and effects that flow from the intervention, regardless of who experiences these (3). Because the chosen perspective determines the outcome of the evaluation, economic evaluations should be explicit about the perspective they adopt (4). Several guidelines on good research practices, such as reported in "Principles of Good Practice for Budget Analysis: Report of the ISPOR Task Force on Good Research Practices - Budget Impact Analysis" and "Consolidated Health Economic Evaluation Reporting Standards 
(CHEERS) Statement" (simultaneous publication in the International Journal of Technology Assessment in Health Care and nine other renowned journals, 2013), have adopted this statement (5-7).

The societal perspective is arguably preferable to the others $(4 ; 8 ; 9)$. This is because health economics is founded on welfare economics, which indicates that an economic evaluation should include the impact of an intervention on the whole of society (4). Accordingly, a societal perspective is necessary for making optimal societal decisions (8). In theory, the definition of the societal perspective, which states that "all costs and effects should be included regardless of who experiences these," seems appropriate. In practice, however, this definition appears less straightforward; looking at costs, the first part of this definition in particular leaves considerable room for discussion as there is often uncertainty regarding which costs should be included in addition to healthcare costs (10). As a result, the way the societal perspective is conceptualized and interpreted can differ among studies, and the choice of conceptualization can seriously affect the outcome of an economic analysis.

While the leading health economic literature explicitly notes that informal care and productivity losses are potentially important (11-13), other costs outside the healthcare sector are given considerably less attention. Yet, the aforementioned definition does not limit researchers to value only informal care and productivity losses along with the use of health services. In fact, interventions within the healthcare sector can yield a wide array of costs and benefits in sectors outside the healthcare sector. These are also known as "intersectoral costs and benefits (ICBs)" (14;15). Drost et al. (2013) identified more than seventy ICBs of healthcare interventions; these ICBs were classified into five categories. These include the sectors "Education" (e.g., special education), "Labor and Social Security" (e.g., productivity), "Household \& Leisure" (e.g., informal care), and "Criminal Justice System" (e.g., police interventions), and a fifth category for "Individual \& Family Effects" (e.g., family conflict), showing that health is connected with the welfare of society through various pathways (14).

Although it is clear that choices are being made when adopting a societal perspective, it is unclear whether choices to omit specific ICBs are made based on a misinterpretation of the societal perspective or measurement issues, and whether an ICB was deliberately omitted or not. There is a danger of leaving out important costs, which can lead to biased results $(10 ; 16)$. This, in turn, could lead to poor investment and reimbursement decisions in the healthcare sector. It is, therefore, important that both researchers and policy makers have sound knowledge of how the societal perspective is conceptualized and interpreted in health economic evaluations, and that both groups have a good understanding of possible discrepancies between these conceptualizations and interpretations. Prior research has already shown that including productivity losses in economic evaluations matters (17). Unfortunately, little is known about the possible impact of other ICBs. Therefore, the main aim of this study is to find out how the societal perspective is conceptualized and interpreted in economic evaluations, and to assess which ICBs are included within these evaluations. A secondary aim is to illustrate how ICBs could determine the results of these evaluations.

\section{METHODS}

\section{Literature Search}

A systematic literature review was conducted focusing on economic evaluations performed from a societal perspective. The reporting of the systematic review was based on a combination of the Preferred Reporting Items for Systematic Reviews and Meta-Analyses (PRISMA) (18) and reporting requirements from the International Journal of Technology Assessment in Health Care.

In July 2015, relevant studies were sought using a design derived from an exemplary literature review (19) and adapted from instructions for retrieving (economic) evaluations $(20 ; 21)$. In addition, to increase the likelihood and efficiency of finding studies reporting the required information, the search was limited to studies that were published after the CHEERS statement was published in 2013. Since the publications of the CHEERS statement appeared between March and June of 2013, it was decided to include only studies published after July 1, 2013. This date was chosen to maximize the number of studies reporting on the perspective considered in the economic analysis, per the CHEERS statement. Furthermore, the search was limited to full economic evaluation studies published in English, with the availability of the complete text, conducted on human subjects.

Databases and search terms were initially selected based on recommendations for retrieving relevant economic evaluation studies, which propose a combined search in PubMed and the National Health Service Electronic Evaluation Database (NHS EED) as an appropriate, cost-effective strategy (20). However, because funding to produce NHS EED ceased at the end of March 2015, we replaced NHS EED with its principle sources: Embase, CINAHL, and PsychINFO. Searches were conducted using the search term combination "societal" AND "economic evaluation" OR "costs". Adding the search term "costs" was necessary to increase the sensitivity of the search, because "economic evaluation" and equivalents are not consistently indexed with Medical Subject Heading terms (20).

\section{Postsearch Article Selection}

Of the studies found, all duplicates, reviews, design articles, and animal studies which passed the search filter were excluded. Two reviewers independently assessed all titles and abstracts (R.D. and I.P.). Titles were selected based on 
a recommendation in the first item of the CHEERS statement, which states that the study's title "identifies the study as an economic evaluation or uses more specific terms such as cost-effectiveness analysis" (CEA) (5). Subsequently, the abstracts were also checked for describing a health economic evaluation. Furthermore, abstracts were checked for use of the word "societal" in combination with either "perspective" or "costs" (or equivalents). Abstracts lacking this combination were excluded.

Finally, full texts (which were all retrieved) were examined for describing full health economic evaluations conducted from a societal perspective. Eligibility criteria, framed around PICOS (22), included all noninstitutionalized and institutionalized age groups of the population $(\mathrm{P})$, independently of the intervention (I), comparators $(\mathrm{C})$, and outcomes $(\mathrm{O})$, set up as trial- or model-based full economic evaluations (comparing both costs and outcomes of both the intervention group and comparators), adopting a societal perspective as study design (S). Only these were included in our study.

\section{Data Extraction and Analysis}

In the second half of 2015, two reviewers (R.D. and I.P.) independently assessed all included studies, after which they compared the assessments. Differences in the results were discussed in author meetings with all authors until uniformity was reached. The data extracted and assessed included conceptualizations of the societal perspective, general study characteristics, and economic evaluation-specific characteristics.

\section{Conceptualizations of the Societal Perspective}

Conceptualizations of the societal perspective (if provided) were labeled as one or more of the following, which were not mutually exclusive: (i) provision of a general conceptualization, that is, mention of broad categories such as "direct costs" and "indirect costs"; (ii) provision of a specific conceptualization, that is, mention of cost types such as "absenteeism costs" and "general practitioner costs"; or (iii) citation of a health economic guideline, journal article, or handbook. Furthermore, we also assessed whether studies specified their conceptualizations further to a specific country context, for example the Dutch or Danish societal perspective.

From here, all conceptualizations of the societal perspective were assessed using content analysis in NVivo version 11 $(23 ; 24)$. This entails an analysis of quotes referring to the societal perspective (e.g., "this study was conducted from a societal perspective, which means...") and was done separately for general and specific conceptualizations. Quotes were defined as general conceptualizations if authors described the societal perspective in generic terms such as "all relevant costs" and did not provide further specifications. If authors did specify relevant costs by mentioning different types of costs (e.g., criminal costs, productivity costs) and/or different cost categories matching the Drummond classification, then this was regarded as a specific conceptualization.

General conceptualizations were analyzed using conventional content analysis, which means that for each new conceptualization a code was added to the overview (23). Specific conceptualizations were analyzed using directed content analysis. Costs were classified based on the $\mathrm{C}_{1}-\mathrm{C}_{4}$ classification of Drummond et al. (2015), which categorizes costs as healthcare costs $\left(\mathrm{C}_{1}\right)$; costs in other sectors $\left(\mathrm{C}_{2}\right)$; patient and family costs, such as out of pocket and travel expenses $\left(\mathrm{C}_{3}\right)$; and productivity costs $\left(\mathrm{C}_{4}\right)(1)$. ICBs (category $\mathrm{C}_{2}$ ) were further subdivided based on a classification scheme by Drost et al. (2013), which provides a sub-classification into the "educational sector," "the criminal justice system," and "household and leisure" (14). The latter covers ICBs related to informal care, social care, household help, leisure time, and voluntary work.

\section{General Study Characteristics}

The general study characteristics extracted from the full text included year of publication, country of study and the disease area targeted by the intervention, based on the International Statistical Classification of Diseases and Related Health Problems 10th Revision (25). Interventions that did not target a specific disease, but overall health such as certain health behavior interventions, were clustered in a separate group. Furthermore, we assessed the type of economic analysis (cost-minimization, cost-effectiveness, cost-utility, costbenefit, combination), study design (trial; modelling), time horizon ( $\leq 1$ year; $\leq 2$ years; $\leq 5$ years; $\leq 10$ years; lifetime), and cost categories included in the evaluation. Types of costs were categorized using the classification schemes of Drummond et al. (2015) and Drost et al. (2013) mentioned earlier $(1 ; 14)$. Costs that were reported as direct or indirect costs were reclassified based on the abovementioned classification schemes.

\section{Economic Evaluation Specific Characteristics}

Specific characteristics of an economic evaluation were drawn from a subset of studies. Based on the general study characteristics, it was decided to restrict this extensive analysis to trial-based economic evaluations of interventions within the disease areas of "musculoskeletal disorders/dysfunction" (13 studies) and "mental and behavioral disorders" (15 studies). For all other disease areas, no more than three trial-based evaluations were identified per area. Furthermore, trial-based evaluations offered revealed (measured) costs, while costs in model-based economic evaluations are (largely) hypothetical. Therefore, and given the limited level of required information provided in these studies, model-based evaluations were not further assessed.

Specific characteristics of economic evaluations extracted from the full text included: the outcome measure (monetary; quality adjusted life years; other), outcome in the analysis 
Drost et al.

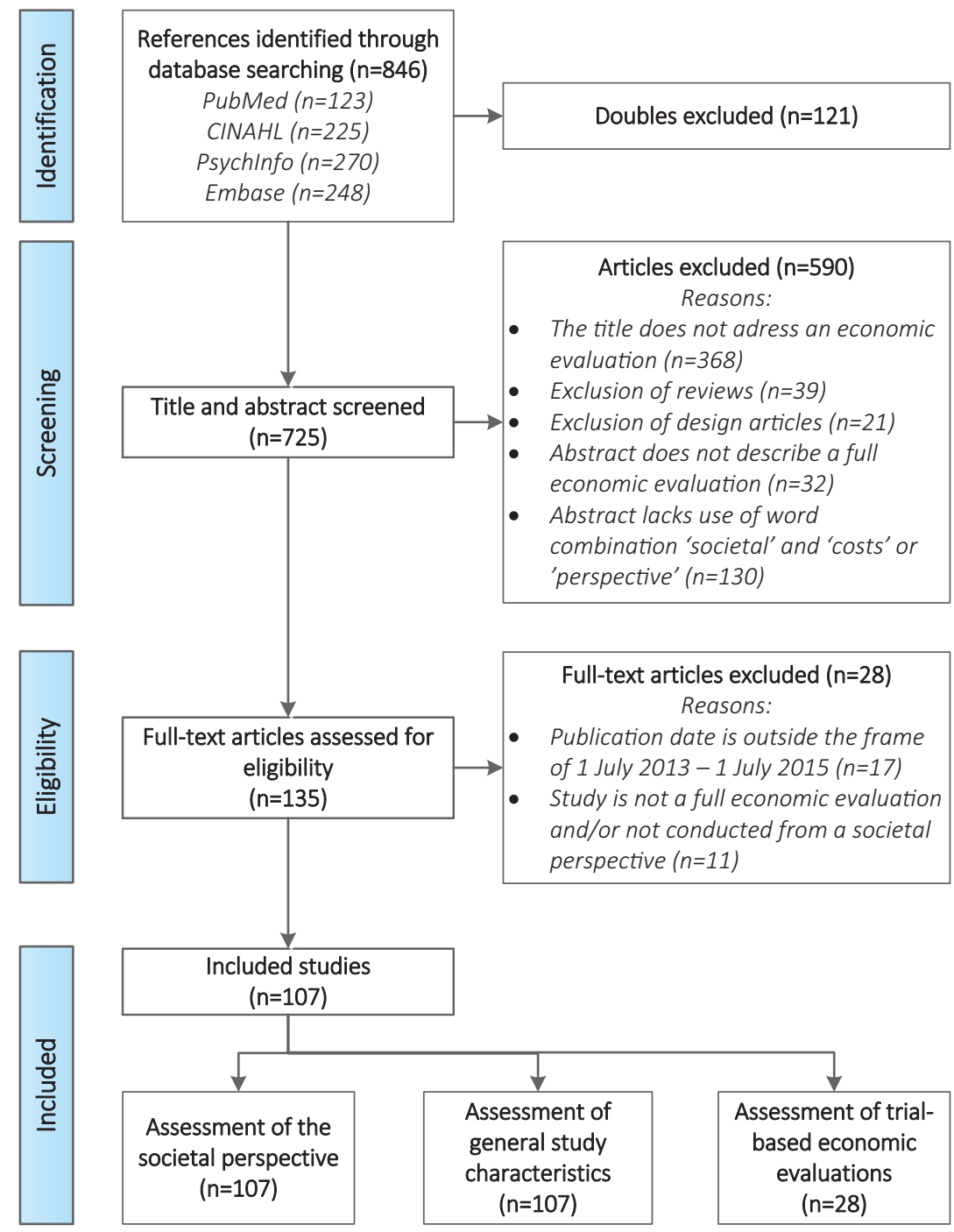

Figure 1. PRISMA flow chart of electronic database search.

conducted from the societal perspective, such as the netmonetary benefit, incremental cost-effectiveness ratio (ICER), and incremental cost-utility ratio (ICUR), whether the intervention was cost-effective and/or had a positive net benefit from the societal perspective, specific types of $\mathrm{C}_{2}$ and $\mathrm{C}_{4}$ costs, whether a second economic analysis was conducted from a different perspective, whether the outcome of this second analysis was different from the one conducted from the societal perspective, and whether the author mentions cost types that were not included in the evaluation conducted from the societal perspective (and if this was considered to be a limitation of the study).

To illustrate how ICBs could impact ICERs/ICURs, for each of these studies and based on available information reported in the articles, we calculated the proportion of ICBrelated costs relative to total costs for the intervention condition(s) and control condition. From here, as has been done for productivity costs in earlier research (17), we recalculated incremental costs (i.e., costs in the intervention condition minus costs in the control condition) by leaving out costs in the educa- tional sector and criminal justice sector. Only these two sectors were assessed, because little is known about the extent to which ICBs in these sectors determine the results of economic evaluations. Main economic evaluation-specific findings are presented and discussed in this study. More detailed information on the trial-based studies can be obtained from the first author.

\section{RESULTS}

Based on the searches in PubMed, CINAHL, PsychInfo, and Embase, 725 unique studies were identified. Of these, 590 were excluded based on an assessment of the titles and abstracts. These were excluded on the basis of being design articles, reviews, not describing the study as being an economic evaluation or not mentioning the societal perspective. Of the $135 \mathrm{left}$, another twenty-eight were excluded, of which seventeen were excluded because they appeared to have been published before 1 July 2013. This resulted in 107 included studies (Figure 1 and Supplementary File 1). 


\section{Conceptualizations of the Societal Perspective}

Of the 107 studies, only 74 provided a conceptualization of the societal perspective. Further analysis showed that, of these seventy-four studies, eighteen studies ( 24 percent) provided a general conceptualization of the societal perspective, fifty studies (68 percent) provided a specific conceptualization, and six studies ( 8 percent) provided both. The other thirty-three studies did not provide any conceptualization of the societal perspective in the text.

In total, twenty-five studies refer to a health economic guideline, journal article or handbook. Sources that were cited two or more times were Gold et al. (1996) (3), Byford and Raftery (1998) (4), Drummond et al. (2005) (26), and the U.S. Panel on Cost-effectiveness in Health and Medicine (which uses the same definition as Gold et al.). Five studies explicitly mentioned that a country-specific societal perspective was used.

In total, ten clusters of general conceptualizations could be identified. (Table 1). The most commonly used conceptualizations were "all costs irrespective of the payer," "all costs from whatever source," and "all costs and benefits irrespective to whom."

Looking at the fifty-six specific conceptualizations (Table 1), types of healthcare costs (34 studies) or productivity costs (33 studies) were named most. Patient and family costs were named in nineteen of the conceptualizations, and fifteen conceptualizations mentioned costs in other sectors. Costs in the educational sector were mentioned in one conceptualization, costs in the criminal justice sector in five and household and/or leisure costs in ten. Intervention costs were mentioned in only ten of the specific conceptualizations. Some specific costs could not be classified based on the specific classification scheme of Drummond (26 studies) and are, therefore, not presented in Table 1. Of these, twenty studies mentioned direct costs, eighteen indirect costs, and one also added intangible costs in the equation. Another eight studies included nonmedical or nonhealth(care) costs. Furthermore, one study divided the included costs into payer, participant, and opportunity costs. Four studies mentioned the outcomes in their conceptualization of the societal perspective. Detailed information on the conceptualizations can be obtained from the first author.

It is important to mention that the costs named in these conceptualizations do not always represent the variety of costs taken into account, for many costs are mentioned elsewhere in the methods and results sections of the articles. For example, most studies included intervention costs in their analysis, while hardly any included these costs in the conceptualization of the societal perspective.

\section{General Study Characteristics}

Around half of the included studies $(n=56)$ covered trialbased economic evaluations and around half $(n=51)$ covered
Table 1. General and specific conceptualizations of the societal perspective ${ }^{a}$

\section{General}

$N=24$

All costs and benefits irrespective to whom 3

All costs irrespective of the payer

All costs to all individuals in society

All relevant costs for and effects on society

Costs shouldered by both provider and household

Any costs incurred by the patients

The overall societal benefits of the program whether intended or not

All relevant costs associated with the burden of the disease

Costs associated with utilization of health care

All costs from whatever source

\begin{tabular}{|c|c|c|c|}
\hline $\begin{array}{l}\text { Specific } \\
\text { Type }\end{array}$ & N & Type & $\begin{array}{l}N=56 \\
N\end{array}$ \\
\hline Intervention costs & 9 & Costs in other sectors & 0 \\
\hline Treatment costs & 1 & Educational sector & \\
\hline Health care costs & 9 & School absenteeism & 1 \\
\hline Community health & 2 & Criminal justice system & \\
\hline Day activity & 1 & Automobile accident & 1 \\
\hline Drug & 2 & Criminal activity & 2 \\
\hline Health care utilization & 1 & Criminal justice & 2 \\
\hline Health system & 5 & Victim & 2 \\
\hline Home care services & 1 & Household \& leisure & \\
\hline Hospital & 9 & Informal care & 6 \\
\hline Laboratory tests & 1 & Household cost & 1 \\
\hline Medical & 9 & Caregiver & 3 \\
\hline Medicare reimbursement & 3 & Housekeeping & 2 \\
\hline Nursing home care & 1 & Absenteeism normal activities & 1 \\
\hline Primary care & 2 & Unpaid work & 1 \\
\hline Provider & 2 & Patient and family costs & 6 \\
\hline Social care & 3 & Mortality & 2 \\
\hline Productivity costs & 25 & Out-of-pocket & 5 \\
\hline Absenteeism work & 8 & Patient time & 2 \\
\hline Disability payment & 1 & Respondent cost & 3 \\
\hline Lost income & 2 & Travel expenses & 6 \\
\hline Lost labour force & 1 & & \\
\hline Work time lost & 6 & & \\
\hline
\end{tabular}

${ }^{a} \mathrm{~A}$ list of references and detailed information can be obtained from the first author. Numbers are based on clear reporting of these types of costs (i.e. literal use of these terms in included articles), and are, therefore, dependent on the quality of reporting. Some reclassification was required given the frequent classification into direct/indirect costs.

modeling studies (Table 2). Approximately one-third of the 107 included studies were U.S.-based $(n=36)$ and more than one-fifth were based in the Netherlands $(n=24)$. Sweden $(n=8)$ and Canada $(n=7)$ took third and fourth place in numbers of included studies. In contrast, a fairly limited number of studies from the United Kingdom $(n=5)$ were included. 
Table 2. Study Characteristics of the Included Economic Evaluations $(n, \%)$

\begin{tabular}{|c|c|c|c|c|}
\hline \multirow[b]{2}{*}{ Study characteristic } & & \multirow[b]{2}{*}{ All } & \multicolumn{2}{|c|}{ Study design } \\
\hline & & & Trial & Modeling \\
\hline Number of studies & & 107 & $56(52)$ & $51(48)$ \\
\hline \multirow[t]{8}{*}{ Country of study } & US & $36(34)$ & $6(11)$ & $30(59)$ \\
\hline & The Netherlands & $24(22)$ & $23(41)$ & $1(2)$ \\
\hline & Sweden & $8(8)$ & $5(9)$ & $3(6)$ \\
\hline & Canada & $7(7)$ & $4(7)$ & $3(6)$ \\
\hline & UK & $5(5)$ & $3(5)$ & $2(4)$ \\
\hline & Spain & $4(4)$ & $3(5)$ & $1(2)$ \\
\hline & Thailand & $4(4)$ & $0(0)$ & $4(8)$ \\
\hline & Other/multiple countries & $19(18)$ & $12(21)$ & $7(14)$ \\
\hline \multirow[t]{14}{*}{ Disease area } & $\begin{array}{l}\text { Musculoskeletal } \\
\text { disorders/dysfunction }\end{array}$ & $22(21)$ & $13(23)$ & $9(18)$ \\
\hline & $\begin{array}{l}\text { Mental and behavioural } \\
\text { disorders }\end{array}$ & $17(16)$ & $15(27)$ & $2(4)$ \\
\hline & Cardiovascular diseases & $11(10)$ & $2(4)$ & $9(18)$ \\
\hline & Infectious diseases & $10(9)$ & $1(1)$ & $9(18)$ \\
\hline & Cancer & $8(8)$ & $3(5)$ & $5(10)$ \\
\hline & Obesity and diabetes & $5(5)$ & $2(4)$ & $3(6)$ \\
\hline & Dental problems & $4(4)$ & $3(5)$ & $1(2)$ \\
\hline & $\begin{array}{l}\text { Kidney and urinary tract } \\
\text { diseases/dysfunction }\end{array}$ & $3(3)$ & $2(4)$ & $1(2)$ \\
\hline & Pain and fatigue & $3(3)$ & $3(5)$ & $0(0)$ \\
\hline & Lung diseases & $2(2)$ & $2(4)$ & $0(0)$ \\
\hline & Hearing disorders & $2(2)$ & $1(2)$ & $1(2)$ \\
\hline & $\begin{array}{l}\text { Pregnancy and neonatal } \\
\text { care }\end{array}$ & $2(2)$ & $1(2)$ & $1(2)$ \\
\hline & $\begin{array}{l}\text { Non-specific (general } \\
\text { health, health } \\
\text { behaviour) }\end{array}$ & $8(8)$ & $5(9)$ & $3(6)$ \\
\hline & Other & $10(9)$ & $3(5)$ & $7(14)$ \\
\hline \multirow[t]{6}{*}{ Type of analysis } & Cost-minimization analysis & $4(4)$ & $3(5)$ & $1(2)$ \\
\hline & Cost-effectiveness analysis & $16(15)$ & $12(21)$ & $4(8)$ \\
\hline & Cost-utility analysis & $55(51)$ & $21(38)$ & $34(67)$ \\
\hline & Cost-benefit analysis & $6(6)$ & $1(2)$ & $5(10)$ \\
\hline & $\begin{array}{l}\text { Cost-effectiveness + } \\
\text { cost-utility analysis }\end{array}$ & $24(22)$ & $17(30)$ & $7(14)$ \\
\hline & Other combination & $2(2)$ & $2(4)$ & $0(0)$ \\
\hline \multirow[t]{7}{*}{ Time horizon } & $\leq 1$ year & $51(48)$ & $44(79)$ & $7(14)$ \\
\hline & $\leq 2$ years & $6(6)$ & $6(11)$ & $0(0)$ \\
\hline & $\leq 5$ years & $9(8)$ & $3(5)$ & $6(12)$ \\
\hline & $\leq 10$ years & $1(1)$ & $0(0)$ & $1(2)$ \\
\hline & Lifetime & $30(28)$ & $0(0)$ & $30(59)$ \\
\hline & Multiple & $3(3)$ & $0(0)$ & $3(6)$ \\
\hline & Unspecified/unclear & $7(7)$ & $3(5)$ & $4(8)$ \\
\hline
\end{tabular}

Although the societal perspective is preferred in international literature (4), it is recommended and commonplace in the United Kingdom to conduct health economic evaluations from the perspective of the NHS (27). The main focus in the U.S. studies was on modeling ( $n=30 ; 83.3$ percent), whereas most of the evaluations in the Netherlands were trial-based $(n=23$; 95.8 percent). The majority of studies $(n=60)$ covered interventions targeting musculoskeletal disorders/dysfunctions, mental and behavioral disorders, cardiovascular diseases, or infectious diseases. Most economic evaluations within the field of mental and behavioral disorders were trial-based (15 of 17 studies), while in the fields of cardiovascular and infectious diseases model-based economic evaluations were more common (18 of 21 studies).

In total, seventy-nine studies were cost utility analysis (CUA)-based, either as a standalone analysis or in combination with a CEA. Most CEAs were trial-based, while the majority of less common cost benefir analyses (CBAs) were model-based. The majority of the trial-based evaluations (78.6 percent) had a follow-up of no longer than 1 year. Apart from one study, which assessed costs over a 1-year timeframe 15 years postintervention, no trial-based evaluations were identified with a follow-up longer than 5 years. Most modeling studies ( 58.8 percent) projected the lifetime costs and consequences of the intervention.

\section{Types of Costs Included}

Nearly all studies clearly report having included intervention costs and healthcare costs (Table 3 ), of which some might have used these terms interchangeably for the same types of costs. Nearly half of the 107 included studies $(n=49)$ included patient and family costs such as out of pocket expenses, travel costs, and/or living costs. The majority of the studies $(n=72$; 67 percent) included costs related to labor productivity, such as costs related to absenteeism, presenteeism, and unemployment. However, productivity costs were more frequently included in studies on interventions targeting musculoskeletal dysfunctions/disorders ( 86 percent) and mental and behavioral disorders (94 percent) than in studies on interventions targeting cardiovascular diseases ( 36 percent) and infectious diseases (60 percent).

Related to this finding, productivity costs were more often included in trial-based economic evaluations $(n=43 ; 77$ percent) than in model-based economic evaluations $(n=29$; 57 percent). Only 38 studies (36 percent) included other ICBs, of which most included only costs related to informal care, household help, and/or social care. Again, these were more frequently included in trial-based evaluations. Studies which included ICBs within the educational sector and criminal justice sector were scarce. Both types were included five times, of which one of the studies that included educational costs was in the field of infectious diseases and two of the studies that 
Table 3. Types of Costs reported to Be Included in Economic Evaluations $(n, \%)$

\begin{tabular}{|c|c|c|c|c|c|c|c|}
\hline \multirow[b]{2}{*}{ Type of costs ${ }^{a}$} & \multicolumn{2}{|c|}{ Disease area } & \multirow[b]{2}{*}{ MH } & \multirow[b]{2}{*}{$C D$} & \multirow[b]{2}{*}{ ID } & \multicolumn{2}{|c|}{ Study design } \\
\hline & All & $M D$ & & & & Trial & Modelling \\
\hline & 107 & $22(21)$ & $17(16)$ & $11(10)$ & $10(9)$ & $56(52)$ & $51(48)$ \\
\hline Intervention costs & $102(95)$ & $20(91)$ & $16(94)$ & $11(100)$ & $10(100)$ & $51(91)$ & $51(100)$ \\
\hline Healthcare costs & $100(94)$ & $20(91)$ & $17(100)$ & $11(100)$ & $10(100)$ & $51(91)$ & $49(96)$ \\
\hline Patient and family costs & $49(46)$ & $8(36)$ & $5(29)$ & $2(18)$ & $6(60)$ & $28(50)$ & $21(41)$ \\
\hline Productivity costs & $72(67)$ & $19(86)$ & $16(94)$ & $4(36)$ & $6(60)$ & $43(77)$ & $29(57)$ \\
\hline Costs in other sectors & $38(36)$ & $5(23)$ & $9(53)$ & $4(36)$ & $2(20)$ & $22(39)$ & $16(31)$ \\
\hline - Household and informal care & $30(28)$ & $5(23)$ & $8(47)$ & $4(36)$ & $2(20)$ & $19(34)$ & $11(22)$ \\
\hline - Leisure and voluntary work & $6(6)$ & $1(5)$ & $2(12)$ & $0(0)$ & $0(0)$ & $4(7)$ & $2(4)$ \\
\hline - Education costs & $5(5)$ & $0(0)$ & $0(0)$ & $0(0)$ & $1(10)$ & $2(4)$ & $3(6)$ \\
\hline - Criminal justice costs & $5(5)$ & $0(0)$ & $2(12)$ & $0(0)$ & $0(0)$ & $2(4)$ & $3(6)$ \\
\hline
\end{tabular}

Note. Based on a thorough full-text analysis by two independently operating researchers. Numbers are based on clear reporting of these types of costs, and are, therefore, dependent on the quality of reporting. Some reclassification was required given the frequent classification into direct/indirect costs.

${ }^{a}$ Classification based on a combination of schemes in Drummond et al. (2015) and Drost et al. (2013) (1, 14). MD, musculoskeletal disorders/dysfunction; MH, mental and behavioural disorders; $C D$, cardiovascular diseases; ID, infectious diseases.

included criminal justice costs were in the field of mental and behavioral disorders.

\section{Impact of ICBs on Economic Evaluation Results}

Of the thirteen trial-based economic evaluations in the disease area of musculoskeletal disorder/dysfunction, nine explicitly reported the follow-up costs for ICBs. All of these reported costs related to labor productivity, such as absenteeism and presenteeism costs. In six of these, (combined) productivityrelated costs took up more than 50 percent of the total costs in both the intervention as well as the control arms. Two studies reported costs related to informal care. In one of these, informal care costs took up 18 percent of the costs in the control condition and 29 percent of the costs in the intervention condition.

In the other study, the weight of these costs relative to the total costs was close to 0 percent. Costs related to other ICBs were not explicitly reported. Seven studies conducted additional analyses from other perspectives: six were from the healthcare/health system perspective and one from the employer's perspective. Differences in results between the societal perspective and other perspectives underlined the important role of ICBs. Six studies explicitly mentioned cost types which were not included in the study, but could have been of importance. The types and number of cost items mentioned in the discussion sections varied per study.

Of the fifteen mental/behavioral health trial-based economic evaluations, thirteen explicitly reported the follow-up costs for ICBs. Twelve of these reported costs related to labor productivity, such as costs of absenteeism and presenteeism. In three of these, productivity-related costs took up more than 50 percent of the total costs in both the intervention as well as the control arms and in all three, presenteeism costs outweighed absenteeism costs. Five studies reported costs related to informal care or domestic productivity. In one of these, informal care costs took up 66 percent of the costs in the control condition and 67 percent of the costs in the intervention condition. In the other five studies, the weight of these costs relative to the total costs was below 20 percent.

Two studies in the field of mental/behavioral health reported costs within the criminal justice sector. In one, crime costs and criminal justice costs took up 25 percent of the total costs in the intervention condition and 18 percent of the total costs in the control condition (28). The recalculation without these costs shifted incremental costs from GBP -350 to GBP $-1,896$. In the other study, costs related to arrests, court, probation, and jail/prison time took up 24 percent of the total costs in the intervention condition and 63 percent of the total costs in the control condition (29). Here, the recalculation resulted in a shift from USD -1,630 to USD -423.

Costs related to other ICBs were not explicitly reported. Eight studies conducted additional analyses from other perspectives: five were from the healthcare/health system perspective, two from the employer's perspective and one from the criminal justice services' perspective. Differences in results between the societal perspective and other perspectives underlined the important role of ICBs. Three studies explicitly mentioned costs which were not included in the study, but could have been of importance.

As mentioned earlier, more detailed information on the trial-based studies can be obtained from the first author. 


\section{DISCUSSION}

\section{Conclusion}

Based on the results, it can be concluded that there is great variety in the way the societal perspective is conceptualized and executed within health economic evaluations. Consequently, there is great variety in the types of costs included in the analyses of the assessed studies.

The authors of included studies who did pay attention to the conceptualization of the societal perspective $(n=74)$ used a general conceptualization, and/or used a specific conceptualization, by mentioning specific costs to describe their interpretation of the societal perspective. Both types were commonly used; eighteen studies used a general conceptualization, fifty studies used a specific conceptualization and six used both. Most of the authors who operationalized the societal perspective in a specific conceptualization explicitly mentioned productivity costs or related terms, which could have been their justification for using the term societal perspective. The classification of costs in (in)direct (non)-medical categories is also found to be widely used instead of the sector-based classification of Drummond.

The conceptualization of the societal perspective was not often mentioned and discussed in the discussion sections of studies. However, some studies did discuss this issue. Some studies regarded their interpretation of the societal perspective to be a weakness of the study $(30 ; 31)$. Others perceived their interpretation of the societal perspective as a strength (32-35).

In trial-based evaluations within the field of musculoskeletal disorders/dysfunction, productivity costs more often took up a large proportion of the total costs than in evaluations in the field of mental and behavioral disorders. However, these costs were shown to be important in this field as well. The two of the mental health studies which explicitly reported costs related to ICBs within the criminal justice sector showed that restricting economic evaluations to healthcare costs and productivity costs alone could sometimes be insufficient. Despite the differences between disease areas and even between studies within these disease areas, this literature review shows that costs related to ICBs often take up a considerable proportion of the total costs of an intervention.

Although this evidence for ICBs other than those related to productivity is scarce, it is clear that, depending on the type of intervention, the disease area, and the target group, omitting ICBs from analyses conducted from the societal perspective could lead to biased results. Furthermore, when this leads to a biased ICER, ICUR or other important health economic outcome, omitting ICBs may lead to poor decision making when choosing between care as usual and an alternative.

\section{Research and Policy Implications}

How the societal perspective is operationalized remains largely in the eye of the beholder (36). Referring to the classification scheme of Drost et al. (2013), it is clear that, even if the societal perspective is chosen, not all 70 ICBs can be or should be included (14). Adopting the societal perspective raises measurement and valuation challenges (10;37). Furthermore, not all ICBs may be considered important enough to be included in the economic evaluations of certain interventions. For example, it is clear that costs within the criminal justice sector are not important for the economic evaluation of blood pressure medication, while the results of this literature review show that they might be important for the field of mental and behavioral health. Although the decision regarding which ICBs to include will remain based on expectations on what are considered to be "big tickets," the results of this literature review underline the importance of making well-informed and argued decisions on which costs to include and exclude from analysis.

Because ICBs are disease-specific, it is advised to always consult experts in the field to know which ICBs are relevant for specific diseases and, accordingly, the interventions targeting these. The ICB classification scheme of Drost et al. can be provided to these experts for them to consult during the process of deciding which ICBs should be measured and valued (14). As mentioned earlier, wrong decisions lead to biased results (10). Our findings affirm the earlier statement of the ISPOR Task Force on Good Research Practices about the wide misunderstanding and misuse of the term "societal perspective" within health economic evaluations (37). Policy makers, therefore, should be vigilant concerning this matter.

The way the societal perspective is conceptualized and executed within health economic evaluations is partly dependent on country-specific health economic guidelines. Looking at productivity costs, a review of Knies et al. (2010) showed that the majority of examined guidelines ( 22 of 30 ) recommend using the societal perspective, but vary in the way productivity costs should be valued (9). However, the use of the term "societal perspective" should not be justifiable merely based on the choice of including productivity costs. Concord with this can be found in the updated version of the Dutch guidelines for costing research, which was published and presented in February 2016. These state that ICBs within the educational sector and criminal justice sector could play a vital role in health economic evaluations as well (38). This goes for all types of analysis, including CEA, CUA, and CBA.

\section{Limitations}

The findings of this study need to be placed in the context of three limitations. First, the findings of the review were dependent on the quality of the reporting in included studies. The amount and quality of information that could be drawn from these studies varied. Some studies were less detailed and structured than others, which made it harder or impossible to retrieve the required information. Furthermore, some elements were harder to retrieve than others. For example, although a 
classification of costs into sectors is considered to provide more structure (1), the majority of studies ( $n=60 ; 56.1$ percent) used the alternative of classifying costs into direct and indirect costs. Therefore, costs had to be reclassified. However, the chance of errors in retrieving and reclassifying information has been minimized through a double and independent analysis by two of the authors.

Furthermore, the choice to include only papers that were published after publication of the CHEERS might have helped. Notwithstanding, what is not reported in papers might be more interesting than what is, and our study was limited due to this (un)deliberate reporting bias. This limitation shows the value of and need for reporting guidelines such as the CHEERS and the Consolidated Standards of Reporting Trials $(5 ; 39)$.

Second, our search for and inclusion of literature was restricted to published research articles, whereas unpublished or gray literature could have provided additional valuable findings. However, it is assumed that the selection made for a broad and sensitive search, and that 107 studies which were included are representative of the way the societal perspective is nowadays conceptualized and interpreted in health economic studies.

Third, several methodological choices needed to be made for feasibility and practical reasons, of which some could be important for future studies. The included studies were not assessed for methodological quality. Furthermore, costs were classified based on the classification schemes of Drummond et al. (2015) and Drost et al. (2013) (1;14), while other ways of classifying costs could have influenced results. Last, the indepth analysis on ICBs was restricted to trial-based economic evaluations on interventions targeting musculoskeletal disorders/dysfunction and mental/behavioral disorders. The number of studies in other disease areas was limited. Recalculation of ICERs was done merely on reported information, not based on the original datasets containing individual patient data, which were not accessible to the authors. Model-based evaluations were not assessed, given the fact that the majority of the modelbased studies did not offer a detailed overview of costs. Furthermore, trial-based evaluations offered revealed (measured) costs, while costs in model-based economic evaluations are (largely) hypothetical.

\section{SUPPLEMENTARY MATERIAL}

Supplementary File 1:

https://doi.org/10.1017/S0266462317000526

\section{CONFLITS OF INTEREST}

The authors have nothing to disclose.

\section{REFERENCES}

1. Drummond M, Sculpher MJ, Claxton K, Stoddart G, Torrance GW. Methods for the economic evaluation of health care programmes. New York: Oxford University Press; 2015.
2. Hutubessy R, Chisholm D, Edejer TT. Generalized cost-effectiveness analysis for national-level priority-setting in the health sector. Cost Eff Resour Alloc. 2003;1:8.

3. Gold MR, Siegel JE, Russel LB, Weinstein MC. Cost-effectiveness in health and medicine. New York: Oxford University Press; 1996.

4. Byford S, Raftery J. Perspectives in economic evaluation. BMJ. 1998;316:1529-1530.

5. Husereau D, Drummond M, Petrou S, et al. Consolidated Health Economic Evaluation Reporting Standards (CHEERS) statement. Int J Technol Assess Health Care. 2013;29:117-122.

6. ISPOR. Health Economic Evaluation Publication Guidelines (CHEERS): Good reporting practices 2016. http://www.ispor.org/ Health-Economic-Evaluation-Publication-CHEERS-Guidelines.asp (accessed August 28, 2015).

7. Mauskopf JA, Sullivan SD, Annemans L, et al. Principles of good practice for budget impact analysis: Report of the ISPOR Task Force on good research practices-budget impact analysis. Value Health. 2007;10:336347.

8. Jonsson B. Ten arguments for a societal perspective in the economic evaluation of medical innovations. Eur J Health Econ. 2009;10:357-359.

9. Knies S, Severens JL, Ament AJ, Evers SM. The transferability of valuing lost productivity across jurisdictions. Differences between national pharmacoeconomic guidelines. Value Health. 2010;13:519-527.

10. Evers SM, Hiligsmann M, Adarkwah CC. Risk of bias in trial-based economic evaluations: Identification of sources and bias-reducing strategies. Psychol Health. 2015;30:52-71.

11. Koopmanschap MA, Rutten FF, van Ineveld BM, van Roijen L. The friction cost method for measuring indirect costs of disease. $J$ Health Econ. 1995;14:171-189.

12. Koopmanschap MA, van Exel JN, van den Berg B, Brouwer WB. An overview of methods and applications to value informal care in economic evaluations of healthcare. Pharmacoeconomics. 2008;26:269280.

13. Weisbrod BA. Economics of public health: Measuring the economic impact of diseases. Philadelphia: University of Pennsylvania Press; 1961.

14. Drost RMWA, Paulus ATG, Ruwaard D, Evers SMAA. Inter-sectoral costs and benefits of mental health prevention: Towards a new classification scheme. J Ment Health Policy Econ. 2013;16:179-186.

15. Weatherly H, Drummond M, Claxton K, et al. Methods for assessing the cost-effectiveness of public health interventions: Key challenges and recommendations. Health Policy. 2009;93:85-92.

16. Drummond M, Sculpher M. Common methodological flaws in economic evaluations. Med Care. 2005;43(Suppl):5-14.

17. Krol M, Papenburg J, Koopmanschap M, Brouwer W. Do productivity costs matter?: The impact of including productivity costs on the incremental costs of interventions targeted at depressive disorders. Pharmacoeconomics. 2011;29:601-619.

18. Moher D, Liberati A, Tetzlaff J, Altman DG, Group P. Preferred reporting items for systematic reviews and meta-analyses: The PRISMA statement. PLoS Med. 2009;6:e1000097.

19. Alayli-Goebbels AF, Evers SM, Alexeeva D, et al. A review of economic evaluations of behavior change interventions: Setting an agenda for research methods and practice. J Public Health (Oxf). 2014;36:336344.

20. Alton V, Eckerlund I, Norlund A. Health economic evaluations: How to find them. Int J Technol Assess Health Care. 2006;22:512-517.

21. Aveyard H. Doing a literature review in health and social care: A practical guide (3rd ed). Berkshire: Open University Press, McGraw - Hill Education; 2014.

22. Schardt C, Adams MB, Owens T, Keitz S, Fontelo P. Utilization of the PICO framework to improve searching PubMed for clinical questions. BMC Med Inform Decis Mak. 2007;7:16. 
23. Hsieh HF, Shannon SE. Three approaches to qualitative content analysis. Qual Health Res. 2005;15:1277-1288.

24. QSR. 2016. http://www.qsrinternational.com/what-is-nvivo (accessed January 18, 2016).

25. WHO. International Statistical Classification of Diseases and Related Health Problems 10th Revision 2016. http://apps.who.int/classifications/ icd10/browse/2016/en (accessed November 9, 2015).

26. Drummond M, O'Brien BJ, Stoddart G, Torrance GW. Methods for the economic evaluation of health care programmes. New York: Oxford University Press; 2005.

27. NICE. Developing NICE guidelines: The manual 2014. https://www. nice.org.uk/article/pmg20/chapter/7-incorporating-economic-evaluation (accessed May 28, 2017).

28. Barrett B, Waheed W, Farrelly S, et al. Randomised controlled trial of joint crisis plans to reduce compulsory treatment for people with psychosis: Economic outcomes. PLoS One. 2013;8:e74210.

29. Herman PM, Mahrer NE, Wolchik SA, Porter MM, Jones S, Sandler IN. Cost-benefit analysis of a preventive intervention for divorced families: Reduction in mental health and justice system service use costs 15 years later. Prev Sci. 2015;16:586-596.

30. Christensen A, Hoy K, Bunger C, et al. Transforaminal lumbar interbody fusion vs. posterolateral instrumented fusion: Cost-utility evaluation along side an RCT with a 2-year follow-up. Eur Spine J. 2014;23:11371143.

31. Lewis DJ, Attiah MA, Malhotra NR, Burnett MG, Stein SC. Anterior surgical management of single-level cervical disc disease: A costeffectiveness analysis. Spine. 2014;39:2084-2092.
32. Golsteijn RH, Peels DA, Evers SM, et al. Cost-effectiveness and costutility of a Web-based or print-delivered tailored intervention to promote physical activity among adults aged over fifty: An economic evaluation of the Active Plus intervention. Int J Behav Nutr Phys Act. 2014; $11: 122$.

33. Imaz I, Rubio B, Cornejo AM, Gonzalez-Enriquez J. Budget impact and cost-utility analysis of universal infant rotavirus vaccination in Spain. Prev Med. 2014;61:116-121.

34. Marsh J, Hoch JS, Bryant D, et al. Economic evaluation of web-based compared with in-person follow-up after total joint arthroplasty. $J$ Bone Joint Surg Am. 2014;96:1910-1916.

35. van Apeldoorn FJ, Stant AD, van Hout WJ, Mersch PP, den Boer JA. Cost-effectiveness of CBT, SSRI, and CBT+SSRI in the treatment for panic disorder. Acta Psychiatr Scand. 2014;129:286-295.

36. Sculpher M, ed. How should a societal perspective in economic evaluation be implemented? Amsterdam: ISPOR; 2014.

37. Garrison LP, Mansley EC, Abbott TA, Bresnahan BW, Hay JW, Smeeding J. Good research practices for measuring drug costs in costeffectiveness analyses: A societal perspective: The ISPOR Drug Cost Task Force report-Part II. Value Health. 2010;13:8-13.

38. ZiNL. De nieuwe richtlijn Economische Evaluaties in Nederland: Verschillen en verbeteringen ten opzichte van de vorige richtlijn. Nieuwe richtlijn economische evaluaties: "Verduidelijking en verdieping". Amsterdam; 2016.

39. Moher D, Schulz KF, Altman DG. The CONSORT statement: Revised recommendations for improving the quality of reports of parallel-group randomised trials. Lancet. 2001;357:1191-1194. 